\title{
La Voluntad de Vida como Potentia en Enrique Dussel
}

\author{
Jairo Alberto Merlo Pinzón
}

Universidad Autónoma de Barcelona, España 


\section{La Voluntad de Vida como Potentia en Enrique Dussel ${ }^{\star}$}

Resumen: Enrique Dussel es el filósofo latinoamericano que más se ha atrevido a pensar el poder político como potentia, como poder indeterminado, que nace de la voluntad de vida y determina la potestas desde su exigencia vital. Este hecho brota de su crítica al poder fetichizado postulado por la modernidad y de la lectura de las tesis voluntaristas de Schopenhauer y Nietzsche que ayudan a vislumbrar la gramática propia de la voluntad como potencia creadora de la potestas que pone de mediaciones para vida.

Palabras clave: Potentia, potestas, voluntad de vida, modernidad, hiperpotentia, plebs.

\section{The Will of Life as Potentia in Enrique Dussel}

Abstract: Enrique Dussel is the Latin American philosopher who has dared to think political power as potentia, as an indeterminate power, which is born of the will to life and determines the potestas from its vital demand. This fact stems from his criticism of the fetishized power postulated by modernity and the reading of the voluntarist theses of Schopenhauer and Nietzsche that help to glimpse the grammar of the will as the creative power of the potestas that mediations for life.

Keywords: Potentia, potestas, will of life, modernity, hyperpotentia, plebs.

Fecha de recepción: 20 de diciembre de 2018

Fecha de aceptación: 13 de marzo de 2019

Forma de citar (APA): Merlo-Pinzón, J. A. (2019). La Voluntad de Vida como Potencia en Enrique Dussel. Revista Filosofía UIS, 18(2), doi: 10.18273/revfil. v18n2-2019010

Forma de citar (Harvard): Merlo-Pinzón, J. A. (2019). La Voluntad de Vida como Potencia en Enrique Dussel. Revista Filosofía UIS, 18(2), 185-205.

Jairo Alberto Merlo Pinzón: colombiano. Magíster en Filosofía Latinoamericana. Doctorando en Filosofía, Universidad Autónoma de Barcelona.

Correo electrónico: jairomerlopinzon@hotmail.com

ORCID: 0000-0002-1957-3218

"Artículo de reflexión derivado de investigación. 


\section{La Voluntad de Vida como Potentia en Enrique Dussel}

\section{Introducción}

Una de las preocupaciones centrales, que Enrique Dussel encuentra en el panorama político moderno y actual, es que el poder ha sido interpretado esencialmente como dominación sobre el Otro, tanto en la teoría como en la práctica política. Para el pensador latinoamericano, grandes reducciones y falacias, como la antropología negativa, el solipsismo, la centralidad el mundo de la vida en la razón, han llevado a la fetichización del poder político.

Para dar cuenta de este proceso, Dussel hace uso de la crítica histórica para ver que la modernidad no comienza, como ha pretendido el discurso hegemónico europeo, con el siglo XVII (esto es más bien una segunda modernidad), sino con el descubrimiento de América en 1492 (primera modernidad) en donde particularmente España, sitiada por el mundo árabe, se encontraba económica y culturalmente en la periferia europea. Por tanto, tras la aparición del continente de las Indias, nuevas dinámicas no solo teóricas sino prácticas comenzaron a forjarse: al encontrarse con comunidades con menor defensa militar, y con la ayuda del hierro y del caballo europeo, comenzó a dominar militar, política, económica, cultural y religiosamente estas tierras. Dicho proceso, afirma el filósofo latinoamericano de la liberación, transformó la condición del ego cogito — presupuesto teórico de la modernidad - en un ego conquiro, como acontecimiento real de la concepción del poder como dominación sobre Otros. Por tanto, Europa, en cabeza de España y posteriormente Portugal, presentó este "ser-señor-dominador" como la visión política por excelencia que terminó "colonizando el mundo de la vida"1:

\footnotetext{
${ }^{1}$ El poder fetichizado crea su propio discurso justificador creado bajo el mito de la modernidad como "encuentro" de culturas; sin embargo, esta concepción tan solo es encubridora de una realidad que fue más cruda de lo que nos podemos imaginar: "Colonización (Kolonisierung)" del mundo de la vida (Lebenswelt) no es aquí una metáfora. Tiene la palabra el sentido fuerte, histórico, real; es la cuarta figura que va adquiriendo el 1492. "Colonia" romana (junto a la "columna" de la ley) eran las tierras y culturas dominadas por el Imperio — que hablaban latín (al menos sus élites) y que pagaban tributo-. Era una figura económico-política. América Latina fue la primera colonia de la Europa moderna sin metáforas, ya que históricamente fue la primera "periferia" antes que el África y el Asia-. La "colonización" de la vida cotidiana del indio, del esclavo africano poco después, fue el primer proceso "europeo" de "modernización", de civilización, de "subsumir" (o alienar), al Otro como "lo Mismo";
} 
La "Conquista" es un proceso militar, práctico, violento que incluye dialécticamente al Otro como "lo Mismo". El Otro, en su distinción, es negado como Otro y es obligado, subsumido, alienado a incorporarse a la Totalidad dominadora como cosa, como instrumento, como oprimido, como "encomendado", como "asalariado" (en las futuras haciendas), o como africano esclavo (en los ingenios de azúcar u otros productos tropicales). La subjetividad del "Conquistador", por su parte, se fue constituyendo, desplegando lentamente en la praxis (Dussel, 1994, pp. 41-42).

Lo que dice Dussel en resumidas cuentas es que la modernidad tuvo que echar mano de aquellos instrumentos teóricos que justificaran estos procesos de expansión y dominación. Sin embargo, en el centro mismo de estas experiencias aparecieron posturas paradigmáticas que dieren cuenta de los desmanes del poder como fetichización. Tal es el caso de Antonio Montesinos, Bartolomé de las Casas, Francisco de Victoria, entre otros, quienes intentaron posturas críticas que cuestionaron la hegemonía dominadora vigente de la época y sus presupuestos teóricos.

Dussel considera que la fetichización del poder generó que teóricamente lo político perdiera el horizonte de su fundamento en las dinámicas vitales del ser humano (potentia) y, como consecuencia, se reflexionara solo desde el poder constitutivo (potestas) y sus partes con el riesgo de sobredimensionarlas al considerarlas como únicas y esenciales: la política como acción estratégica (Maquiavelo), como teleología instrumental; medio-fin (EE.UU.), competencia amigo-enemigo (Schmitt); hegemonía (Gramsci); consenso discursivo como negociación de acuerdos para superar conflictos (Habermas); súper estructura de lo económico (cierto marxismo estándar que elimina lo político) ${ }^{2}$; independencia de lo económico (economicismo anti-político de la posición liberal); referencia al Estado (Foucault); afirmación-negación de principios normativos (Apel, Rorty, Laclau), etc.

pero ahora no ya como objeto de una praxis guerrera, de violencia pura — como en el caso de Cortés contra los ejércitos aztecas, o de Pizarro contra los incas-, sino de una praxis erótica, pedagógica, cultural, política, económica, es decir, del dominio de los cuerpos por el machismo sexual, de la cultura, de tipos de trabajos, de instituciones creadas por una nueva burocracia política, etc., dominación del Otro. Es el comienzo de la domesticación, estructuración, colonización del "modo" como aquellas gentes vivían y reproducían su vida humana (Dussel, 1994, pp. 49-50).

${ }^{2}$ Dussel afirma que, "para el marxismo estándar, lo económico debe ser completamente planificado desde los órganos políticos. Se intenta una plena racionalización anticipada de la economía sin mercado (otro postulado ideal pleno de la modernidad). El Estado planificador termina eliminando la política (ya que desaparece la esfera de legitimidad democrática, la intervención autónoma y libre de los ciudadanos, la discusión razonable de las opciones para llegar a acuerdos que obliguen subjetivamente a la adhesión al consenso compartido). La pretensión de plena planificación reduce la política a la administración (razón instrumental), y destruye la institución del mercado, que, aunque nunca produce equilibrio (y por ello es necesaria una cierta intervención estratégica, inteligente y mínima de planificación democrática), es sin embargo necesaria" (Dussel, 2013, p. 76). 
Lo que está de fondo por una parte es el olvido de la complejidad del campo $^{3}$ político en el que intervienen ${ }^{4}$ sujetos (actores) singulares (pero a la vez intersubjetivos) —con "voluntad y con un cierto poder" (Dussel, 2006, p. 16) en sistemas e instituciones; pero por otro, la falta de considerar suficientemente el horizonte ontológico que contiene la vida humana y que expresa el determinante fundamental y la "última instancia de todas las instancias o campos" (Dussel, 2009a, p. 33) de lo que es la política. Por ende, el interés de Dussel consiste en propiciar un despliegue arquitectónico de lo político que se abra a una complejidad necesaria, mínima pero suficiente (2009a, p. 37), para construir categorías, niveles, esferas, campos, sistemas, entre otros, que mapeen críticamente la política desde los contextos donde se ha formado y se proyecte como servicio a la humanidad y no como dominación.

Esta postura crítica de Dussel recoge experiencia política latinoamericana en sus luchas por su liberación (unas veces con éxito y otras no) en donde el poder se reclama sobre la comunidad-pueblo y no solo sobre un individuo (el representante). Esto ha exigido resignificar y cargar de un nuevo sentido semántico los conceptos de los que se ha valido el poder fetichizado ${ }^{5}$ en torno a la teoría política y desplegarlos críticamente para la construcción de un nuevo orden (una nueva hegemonía) con mayor pretensión de verdad, bondad y justicia universal.

El proyecto dusselniano implica una comprensión positiva de poder político ${ }^{6}$ a diferencia de la tendencia moderna que propició su teorización desde la

\footnotetext{
${ }^{3}$ Dussel advierte que "usaremos el concepto de campo en un sentido aproximado al de Pierre Bourdieu. Esta categoría nos permitirá situar los diversos niveles o ámbitos posibles de las acciones e instituciones políticas, en las que el sujeto opera como actor de una función, como participante de múltiples horizontes prácticos, dentro de los cuales se encuentran estructurados además diversos sistemas y subsistemas, en un sentido semejante al de Luhmann. Estos campos se recortan dentro de la totalidad del "mundo de la vida cotidiana". Nos interesan especialmente los campos prácticos" (2006, p. 15).

${ }^{4}$ Los campos políticos juegan un papel de interdependencia compleja: "Hemos dicho que la política se despliega en un campo propio como todas las demás actividades humanas. Los más variados campos no son independientes, sino que se cruzan, se determinan - la palabra inglesa overlapping deja entender bien el concepto-; hay un cruce de los campos con los campos; de campos con sistemas; de sistemas con sistemas, etc. La complejidad queda siempre abierta a la aparición de nuevos campos o sistemas, a la desaparición de alguno, a la mutua determinación (nunca absoluta) que cambia en el tiempo y el espacio" (Dussel, 2009a, p. 40).

${ }^{5}$ Término usado innumerables veces por Dussel (bajo la perspectiva crítica del joven Marx): "la extraña palabra "fetichismo" viene del portugués. En esta lengua feitiço significa "hecho" (la " $\mathrm{h}$ " se transforma frecuentemente en "f" por ejemplo en "fechoría": o "hermosa" en "formosa" la isla del Pacífico). "Los hechos por la mano de los hombres", son ídolos. Fetichismo e idolatría es semejante. Es un hacer "dioses" como producto de la imaginación dominadora del ser humano; dioses hechos que luego se les adora como divino, lo absoluto, lo que origina el resto" (Dussel, 2006, p. 40; 2013, p. 51).

${ }^{6}$ En el mundo griego, de manera especial Platón, se hace una descripción positiva del poder al presentarlo como el ejercicio de la virtud de los gobernantes, donde el filósofo era su mejor representante; sin embargo, esta concepción no supera la unilateralidad del poder en un solo individuo dejando a la comunidad aparte en el campo político; o si se mantenía la permanencia de un gobierno con la democracia aristotélica, las referencias al pueblo-comunidad se quedan cortas frente a la importancia de la singularidad ciudadana y mucho más si esta es disidente.
} 
defectividad (como dominación sobre otros). Dicha tendencia estaría sujeta a la desconexión con el fundamento, es decir, del pueblo, como sede original del poder. Si no se arriesga a una interpretación positiva del poder, el noble oficio de la política, afirma Dussel (2013, p. 135), pierde su pretensión de honestidad y justicia, pues: "¿Quién desearía comprometerse a una responsabilidad política si es intrínsecamente perversa, corrupta, un verdadero pacto fáustico con el diablo como llega a expresarlo Weber?" (Dussel, 2009a, p. 24). La política contemporánea requiere con urgencia una posición distinta en donde el servicio, la efectividad institucional, la representatividad soberana de un pueblo estén ligadas a una ética que nazca del compromiso de la vida y promotora de la misma.

Para lograr su cometido categorial, Dussel hace el ejercicio metodológico de descubrir aquellos elementos que son generadores primarios frente aquellos que son disyuntivos o segundos, por eso expone el término potentia como generador de la potestas o, en otras palabras, como contenido material que condiciona el contenido formal de la política. También recurre a la comprensión crítica de las categorías de "totalidad" y "exterioridad" para ver de manera especial cómo opera la potentia en un todo constituido.

\section{La Voluntad de Vida como Potentia creadora de la Potestas}

Dussel entiende que el poder implica un análisis ontológico. Sabe muy bien que la comprensión defectiva del poder tiene como condición una determinada comprensión del ser que se ha extendido y ha penetrado la interpretación política, sobre todo, moderna. Su crítica le lleva a condensar los aportes schopenhauerianos y nietzscheanos en su postulación del poder como voluntad de vida.

La primera gran crítica que se puede demostrar es la tendencia occidental a comprender el "ser como algo meramente sabido" (según la exposición de Parménides ${ }^{7}$ ) que queda reductivamente en los parámetros del lenguaje ${ }^{8}$ y de la razón, como lo ha expuesto Nietzsche en el corpus de sus obras, pues la metafísica occidental del "ser" eclipsó el mundo de la vida, del sentir, de la voluntad y del devenir, potenciando, por el contrario, el reinado de la moral sobre la vida, las lecturas lineales de la historia, la lógica binaria, la decadencia, etc.:

Los filósofos creen que honran algo cuando lo sacan de la historia, cuando lo conciben desde la óptica de lo eterno, cuando lo convierten en momia. Todo lo que han estado utilizando desde hace miles de años no son más que momias conceptuales; nada real ha salido con vida de sus manos. Cuando esos idólatras honran algo, lo matan y lo disecan [...] Para ellos, la muerte,

\footnotetext{
7Parménides dice: "porque pensar y el ser son la misma cosa" (Parménides y Heráclito, 1977, p. 50); también Descartes llegará a una conclusión parecida: "Pienso luego existo" (Descartes, 2013, p. 116). ${ }^{8}$ La unidad del ser queda garantizada a pesar de las formas accidentales que se pueden percibir, por eso "El ser se dice de muchas maneras".
} 
el cambio, la vejez, al igual que la fecundación y el desarrollo constituyen objeciones, e incluso refutaciones. Lo que es, no deviene; lo que deviene no es [...] pero como no pueden apoderarse de lo que es, tratan de explicar por qué se les resiste [...] los sentidos (Nietzsche, 2007, p. 29).

Nietzsche hace volver a las intuiciones de Heráclito ${ }^{9}$ con la idea de cambio, movimiento, impulso, esfuerzo, y hace pensar que "el ser se resiste conceptualmente" (como algo meramente sabido) y más bien obliga a otras formas de aprehensión de dicha realidad. Para "el loco de Torino" el ser es algo más bien querido (sentido) en sí mismo por la voluntad de poder.

Por otra parte, Dussel se apoya también en Schopenhauer quien habló de la "la voluntad de vivir" que reina en la realidad circundante y considera que a dicha afirmación le hace falta una clarificación: "el que quiere es un viviente que tiene una inmediata-experiencia de sí y solo cuando hay vida puede encontrarse "su querer" o mejor, su "voluntad de vivir", por eso es más exacto decir "voluntad de vida" (2009a, p. 48).

El reconocimiento del cuerpo, primeramente, como la "más alta manifestación" de dicha voluntad de vivir (Schopenhauer) o como la noción más sorprendente ${ }^{10}$ y sensata (Nietzsche) es el lugar común de diálogo con Dussel. Es un cuerpo "viviente", material, el que quiere el aumento y el desarrollo de la vida, pero él no es solamente ocasión de demandas (necesidades básicas para la existencia), sino en cada cosa — como se profundizará- y en sí mismo, tiende a una "profunda realización"11 (Dussel, 2009a, p. 49). Por tanto, el cuerpo no solo sería una noción desde la cual se podrían replantear y construir los contenidos materiales de la ética y de la política, sino una comprensión más elevada y completa del ser. Nietzsche, al respecto, dice:

El cuerpo humano en el que repercute, siempre, vivo y vivaz, el pasado más remoto y más próximo de todo el devenir orgánico, por encima y por fuera del cual parece recorrer un prodigioso e inaudito rio: el cuerpo es la noción más sorprendente que la antigua "alma" (2008, p. 437).

\footnotetext{
${ }^{9}$ Recordemos que Heráclito proponía el principio metafórico del fuego para expresar la idea de cambio en un mundo de contrarios (inherente en cada cosa). Su más famosa frase expuesta en el Cratilo de Platón con la que demuestra el flujo universal de los seres (devenir), reza; "no se puede entrar dos veces en el mismo rio"

${ }^{10}$ Deleuze presenta a partir de Nietzsche —en la sección sobre el Cuerpo- una noción que se extiende incluso hasta la colectividad orgánica o social en donde interactúan distintas fuerzas: “¿Qué es un cuerpo? Solemos definirlo diciendo que es un campo de fuerzas, un medio nutritivo y disputado por una pluralidad de fuerzas [...] lo que define a un cuerpo es esta relación de fuerzas dominantes y fuerzas dominadas [...] Se llamará jerarquía a esta diferencia de las fuerzas cualificadas, conforme a su cantidad: fuerzas activas y reactivas" (p. 60).

${ }^{11}$ Es la experiencia ética y estética de la vida que difiere de una existencia netamente entendida bajo el reino de las demandas básicas de la existencia. En la vida también está la generosidad, la solidaridad, la apertura al Otro, y no solo su instrumentalización para fines egoístas.
} 
Schopenhauer postula que la mayor objetivación de la voluntad se da en corporalidad, pero enriquecida por la exposición nietzscheana, esta realidad física (espacial y temporal) de la voluntad de un viviente que quiere vivir lleva a mirar que el cuerpo expresa el poder como una consecuencia ni un agregado ${ }^{12}$, sino que es algo constitutivo (vital); es decir, es la fuerza-potentia de la misma voluntad que "abre el ámbito de todo lo querido desde un por-sí-mismo como el que maneja y controla lo que pone y en cuanto quiere ponerlo desde su soberanía, su ser-señor, su Poder-poner" (Dussel, 2009a, p. 51). Posiblemente esta descripción, es un intento desde la gramática de la voluntad (desde el filósofo de Danzig y Nietzsche) por responder someramente a la inquietud misma que Spinoza (2013) presentaba en el escolio I de la proposición II, de la tercera parte de su Ética: "qué es lo que puede un cuerpo". Los elementos expuestos hasta aquí muestran que lo que puede es precisamente eso: "poner" desde su condición vital. Se puede afirmar con Dussel que la "esencia del poder es la voluntad, pero la esencia de la voluntad es la vida" (2009a, p. 47) y la vida se manifiesta en un cuerpo. El que quiera y pueda un cuerpo ${ }^{13}$ viviente, es una condición indispensable del modo propio como opera su potencia:

La voluntad sin su poder no obraría, nada podría hacer. El poder sin las posibilidades, los entes-mediaciones queridos y puestos en la existencia como "condición" de su propia realización, no podrín ejercerse. Sería un poder vacío, sin poder contar con nada para operar. Los entes-valiosos son las condiciones de realización de la propia vida, de la voluntad y del poder (2009a, p. 51).

Nietzsche presentaba la voluntad de poder como la condición esencial de cada ente. Dicho poder de la voluntad se ejercía ordenando (creando) la realidad a la medida de su exigencia existencial (dionisiaca). Lo puesto de manera creativa se hace portador de valor desde la voluntad que tiene fuerza de jerarquizar mediaciones posibles como expresión de la misma vida.

\footnotetext{
${ }^{12}$ Esta inherencia del poder es noción central de Dussel que se postulará crítica como el actuar de un pueblo: "el poder es una facultad, una capacidad, que se tiene o no se tiene, pero con precisión nunca se toma. Los que pueden asaltarse, tomarse, dominarse son los instrumentos o las instituciones que consisten en las mediaciones de su ejercicio (como cuando se dice en la Revolución Francesa: "la toma de la Bastilla", que era una cárcel, edificio de la institución jurídico-punitiva del Estado monárquico absolutista)" (2006, p. 29).

${ }^{13}$ Para Dussel, Hegel hace una importante distinción cuando muestra que el ser (al comienzo de su filosofía del derecho) es totalmente indeterminado; como voluntad, es completamente libre de toda determinación y sin contenido alguno de ente (Dasein). Análogamente, la potencia es el ser indeterminado que sin la potestas queda vacía, no tendría ninguna realización; sin embargo, esto no quiere decir que la potentia no posea cierta autonomía que interpela a su propia determinación. Hemos visto que, en una lectura más acertada de Aristóteles, la potencia es potencia de no ser-hacer, de no fijarse, de ser excepción en el estilo schmittiano, pero más que eso, de ser rebelión en formato dusselniano.
} 
Para Dussel, la voluntad "es la potencia que se potencia como poder" (2009a, p. 46) de instaurar entes que comportan valor puestos desde sí y solo tienen razón de ser si sirven a la voluntad de vida, de lo contrario, la misma potencia de la voluntad puede suprimirlos e instaurar otros o puede modificar lo que ha perdido valor vital.

Así funciona la dinámica de la voluntad: sin el querer la voluntad no puede, pero la voluntad en sí no puede "no querer", aun en las situaciones más delicadas donde la vida pierde aparentemente su sentido, pues se antecede "al no querer determinada condición de vida", el querer mismo que Schopenhauer describía como un "impulso ciego" e "irracional" latente eternamente, que condiciona toda la existencia: es su querer-poder esencial, que solo se puede separar de forma conceptual y explicativa. Por tanto, tendríamos que decir con Dussel que la voluntad sin su poder no obraría y, más profundamente, no existiría como tal. La voluntad tiene entonces el poder y el querer como constitución y como capacidad determinativa en lo que pone con fuerza transformadora y creadora: lo "puesto" puede ser "de-puesto" y "sobre-puesto" desde su exigencia vital.

Nietzsche expone que los valores son condiciones condicionadas, que en tanto "condiciones" se asegura su propia consistencia, pero "condicionadas" porque depende de la "voluntad de poder". Se trata del momento de la fijación (potestas) del acto de poder creador de un sujeto que ordenando la realidad la valoriza desde sí; es el ente práctico (incluso como estructura o institución) el que es portador de dicho valor y, por ende: "los entes valiosos valen como mediaciones de la vida" (Dussel, 2009a, p. 53). Sin embargo, en su "totalidad" afirma Dussel desde la lectura de Marx, tienen más bien "dignidad" (v.gr. la vida misma, el trabajo, etc.) como fuentes creadoras de valores. Así pues, lo propio de la voluntad de poder es poder-poner-valor-orden, como mediación o condiciones necesarias para la vida y esto es su sentido profundo: "El mundo se abre entre esos extremos de la temporalidad viviente, y los entes pueblan el mundo como posibilidades para la vida" (2009a, p. 49).

La vida es la que quiere poner mediaciones, es decir, entes, pero no lo hace solo en el sentido del saber, sino de su practicidad, de su disponibilidad para desplegar y asegurar condiciones vitales; es por eso, que este poder-poner (en la praxis y cognitivamente) se muestra como acto esencial positivo de la voluntad que nada tiene que ver con dominación-fetichización. Si en algo ejerce su señorío, es en su capacidad —dijimos- de determinación para poner los medios valiosos (valores relacionados en una totalidad) en la temporalidad de la vida.

Ahora bien, una cuestión se asoma a la reflexión al posicionar el poder desde una comprensión vital: ¿cuál vida es la que se quiere?, ¿qué tipo de vidaser es subsumida en el ente?, ¿qué modo de vida debe argumentarse como la 
consideración más alta y digna de ser la fuente de estos argumentos? Dussel se detiene en este punto y se ve obligado a escindir el concepto de vida, más allá de la descripción autoreferencial de la voluntad de vivir que propició la modernidad en la teoría política.

Según su explicación, la teoría solipsista de la "naturaleza salvaje y conflictiva" (como lo testimonian Hobbes, Smith, Spinoza, Schopenhauer, entre otros) se debe a las dinámicas del mercado en las ciudades europeas que gestionó un argumento teórico o formalismo hipotético, como lo llama Dussel (2001, p. 174), elevada de la experiencia del mercado como base de una construcción filosófica y política moderna. Sucedió que la competencia mercantil de las pequeñas ciudades era la única manera de cambiar las condiciones vitales y se generalizó este hecho como forma universal del comportamiento humano.

Por ejemplo, Spinoza — una de las fuentes del pensador argentino-mexicano en cuanto a la descripción de conservación de la existencia- cayó en esta visión extendida de interpretación moderna. Sutilmente, describió el conatus como fuerza, poder, capacidad que se procura sobre todas las cosas o sobre el Otro, su propio beneficio. Y solo lo otro o el Otro (como agente externo) puede causar su destrucción. Es una lucha sin tregua si no se media con el pacto. La exposición de Spinoza reproduce una antropología negativa y conflictiva entre individuos que quieren sobrevivir para mantenerse en la vida a cualquier costo:

El "estado de naturaleza" como solipsismo egoísta, negativo, salvaje, sobrevivencia contemplaba exclusivamente su egoísta permanencia por la búsqueda del propio interés sobre el bien común. Es interesante observar que Spinoza repite frecuentemente que en el estado de naturaleza se tiene una "pulsión de conservación en el ser"; es, exactamente, el momento de la producción y reproducción de la vida humana, pero interpretada reductivamente como sobrevivencia animal y desde una lucha a muerte fuera de toda civilidad. En cambio, como hemos visto en la Ética de la Liberación, la reproducción de la vida humana es siempre cultural y racional, y según pulsiones reproductivas también humanas. La concepción reductivista de la vida, de la afectividad como egoísta e irracional, destruye el nivel material que quedará ausente de la filosofía política moderna —al menos en la hegemónica- (Dussel, 2001, p. 175).

Lo que Dussel en últimas hace en este punto es descubrir las reducciones del ámbito material de la política proporcionados por los presupuestos teóricos de la sociabilidad negativa que construyó la modernidad. Uno de los grandes errores de esta época fue su incapacidad de reconocer en la vida la experiencia comunitaria como intersubjetividad fundamental ${ }^{14}$ y propiciar, por el contrario, la individualidad

\footnotetext{
${ }^{14}$ Para Dussel la voluntad comunitaria, es voluntad plural de todos (o "general" en el sentido de Rousseau) o de la mayoría hegemónica que llega al consenso a través de acuerdos discursivos para poner mediaciones (poder-poner).
} 
como momento de "naturaleza salvaje" que solo puede ser superado por un estado civil a través del pacto (Dussel, 2001, p. 177). Como consecuencia, la facultad de la razón bajo esta perspectiva se centraliza (eclipsando todas las demás dimensiones vitales) y solo adquiere un carácter instrumental-estratégico que afecta la voluntad individual por una voluntad general; como propone Spinoza, una "razón superior", que se concretiza en la fórmula del "poder del Estado" como garante de mediación en la situación conflictiva. La voluntad individual como posibilidad de disenso frente a la totalidad es vista como enemiga ${ }^{15}$. Así pues, la vida en el ámbito político queda sujeta al marco instrumental por exigencia utilitarista del pacto: no hay una normatividad ética material que sustente la política, sino solo sus razones en acuerdos. La individualidad pierde su libertad porque es sometida al poder del Estado que puede "dominar legítimamente":

El conatus esse conservandi del "estado de naturaleza" terminó por imponerse extrañamente en el "estado civil": la pulsión de reproducción del sistema formal o político establecido juzga como la perversidad suprema la pulsión dionisíaca de transformación. Se trata de una política que de revolucionaria en Spinoza hoy se transformará en conservadora, surgida de la burguesía mercantil triunfante holandesa que se tornará totalitaria (Dussel, 2001, p. 180).

Si se escinde el concepto "vida"16, superando y criticando la referencialidad solipsista, se translucirá el ámbito olvidado de la experiencia comunitaria ${ }^{17}$. Por otra parte, la voluntad de vida no solo pone mediaciones para su aumento y conservación (como si fuera un acto mecánico), sino que busca en "todo" una profunda realización: el acto mismo de conservarse, desarrollarse y aumentarse (expresado en la alimentación, el abrigo, la sexualidad-procreación, etc.), a diferencia de los animales, tiene una carácter estético en sentido amplio, pues, si se busca vivir, lo que se proyecta en cierto sentido es "un buen vivir" o "una buena vida", que se abre a la temporalidad como ocasión de lectura (pasado) y posibilidad (futuro) desde el presente, es decir, que la vida es capaz de ser pensada desde un momento de mayores condiciones vitales (profundas realizaciones vitales) y puede vislumbrarse como esperanza, como posibilidad de una mayor realización vital, con la cual, la existencia se abre campo para instaurar o para luchar por otra forma posible y digna de existencia.

\footnotetext{
${ }^{15}$ Spinoza lo expone así "Entienda que es enemigo aquel que vive fuera del Estado y no reconoce su soberanía ni como súbdito ni como aliado. Porque el enemigo del Estado no lo hace el odio, sino el derecho" (2005, p. 246).

${ }^{16}$ En la Ética de la Liberación de Enrique Dussel el concepto de vida tiene unas características especiales resumidas en la tesis 3 de dicho libro (2009b, p. 618). Allí se hace la respectiva salvedad frente a posiciones vitalistas materialistas o racionalistas reductivas que han proporcionado algunas reflexiones filosóficas.

${ }^{17}$ Dussel argumenta que incluso en el mundo primitivo la comunidad mostraba su "organización", su unión de voluntades por el querer vivir (sobre-vivir) dándose razones en acuerdos como "poder discursivo" (Habermas). Entonces, la astucia de la vida estaba y está en darse razones-práctico-políticas para las posibilidades de esas vidas.
} 
El filósofo mendocino lo asevera: "la vida sí, pero toda la vida" (Dussel, 2011, p. 165). Uno de los grandes problemas de la política actual es que se afirma la vida tan solo en una dimensión provocando reductivismos teóricos. Por el contrario, la vida afirmada tiene que serlo en su totalidad (temporal, contextual, comunitaria, etc.) y no solo en una de sus posibilidades. Por ejemplo, hoy más que nunca debe afirmarse la vida en su entorno, en su experiencia ecológica, ya que en la reflexión filosófica y política la posibilidad de muerte del mundo no había sido pensada hasta ahora como tal. Los acontecimientos que muestran la fragilidad de los ecosistemas (el calentamiento global, la contaminación a distintos niveles, la desaparición de determinadas especies, la aparición de nuevas enfermedades, etc.) y la dependencia total de la vida humana a estos, evidencian sencillamente que la vida sin su entorno no es posible:

iDebemos en todo actuar de tal manera que la vida en el planeta Tierra pueda ser una vida perpetua! Esto es, además, un postulado. Los bienes no renovables son sagrados, irremplazables, inmensamente escasos. Es necesario ahorrarlos en extremo para las generaciones futuras. Es quizá la exigencia normativa número uno de la nueva política (Dussel, 2006, p. 104).

La vida humana es co-dependiente hoy más que nunca de la vida del planeta tierra, es decir, del entorno que comparte comunitaria y corresponsablemente con los otros. Tras el ejercicio de escindir el concepto de vida, el concepto de razón (y no solo instrumental con el que se justifica la dominación ${ }^{18}$ ) se aprecia en su papel práctico-material y discursivo que ayudaría a postular los principios (materiales, formales y de factibilidad) con pretensión de bondad, verdad y validez universal con los cuales se construye la realidad política. Así pues, el poder viene dado por la unión de voluntades de una comunidad en la que cada uno es constituido intersubjetivamente (Dussel, 2009a, p. 56). Cabe recordar, una y otra vez, que la gran tendencia de la teoría del poder moderno acentuó el "estado de naturaleza" que había que superar, anulando voluntades de la mayoría y posicionando el poder en un solo actor político: el soberano. Esta única voluntad "más poderosa" es comprendida "desde arriba" porque tiene que reprimir o controlar a los otros, a "los de abajo" (los obedientes) haciendo sentir su poderío (o mejor la concentración del poder) y en esto ha consistido su legitimidad como expone Weber. Este tipo de voluntad individual aparentemente legítima se justificó a sí misma en figuras como la de "Dios" (religión), el linaje de los fuertes, la tradición, etc. Aunque en ocasiones resultara "efectiva" para la organización social, generalmente actuaba injusta, despótica e ilegítima sobre la comunidad.

\footnotetext{
${ }^{18}$ Dussel anuncia esto no solo desde un proyecto político, sino también ético: "La ética de la liberación subsume así el momento crítico de los "grandes críticos" (Feuerbach, Schopenhauer, Nietzsche, Horkheimer, Adorno, Marcuse, y particularmente Marx, Freud y Lévinas) en cuanto ellos critican aspectos de lo que de "dominadora" tiene la modernidad, la razón moderna. Pero la ética de la liberación puede igualmente, contra el irracionalismo de algunos de estos críticos (por ejemplo, Nietzsche y los postmodernos), defender la universalidad de la razón en cuanto tal, y en especial la razón ético crítica, a la que nada le está vedado. Pero puede defender la universalidad de la vida, de la corporalidad, etc., en una complejidad mayor" (2009b, p. 311).
} 
En otras palabras, cuando la reflexión política moderna pensó la "unión de las voluntades" no aclaró o no ha podido discernir el lugar de la individualidad (solo la logró comprender en la voluntad del soberano); por el contrario, la postulación complementaria de la intersubjetividad que construye a la comunidad de vivientes no se trasluce para Dussel como una suma de identidades, sino en una individualidad de organización heterogénea, disciplinada y práctica con los Otros para vivir (sobre-vivir-convivir); la representatividad no abandona en ningún momento a la comunidad, al pueblo, sino que la voluntad individual (intersubjetiva) que es a la vez comunitaria sufre la determinación en unión de voluntades por el consenso discursivo y por poner medios desde y para la vida. Dicho poder aunado de la voluntad general debe llegar a ser desplegado en las instituciones y a su vez verificado como un "poder obediencial" (por su pretensión de verdad, bondad y eficacia) que viene desde "abajo", no por inferioridad, sino por su tensión constante con el "fundamento fundante", es decir, con la vida que tiene potentia para organizarse políticamente.

\section{La Dinámica de la Potencia: Pueblo y Populismo}

¿Cómo obra la potentia? Agamben advertía la no suficiente comprensión de la idea aristotélica de potentia. Decía, además, que la potencia no solo aparecía en el ente como un modo de ser-hacer, sino también de no ser-hacer. El mismo Aristóteles en su Metafísica lo escribía explícitamente: "toda potencia es impotencia de lo mismo y con respecto a lo mismo" (IX 1046a, 32). Esto quiere decir, que la potencia tiene la capacidad de "mantenerse en suspenso" para no desaparecer (Agamben, 2013, p. 63) y presentarse (reaparecer) como una nueva condición que reformula al acto.

Desde otra perspectiva, la dinámica de dicha potentia se expresaba en la voluntad como impulso infinito del "querer vivir" que no desaparece como lo expuso la teoría voluntarista de Schopenhauer. La perennidad de la voluntad general en el mundo particularizada en cada individuo podría llegar a ser aquietada hasta una aparente "negación de la voluntad de vivir" a través de distintos medios como la actitud artística, la conmiseración y la resignación, pero esto no significa su aniquilación realmente.

Ahora bien, Enrique Dussel mostraba que las grandes reducciones de los teóricos de la voluntad (en este caso Schopenhauer y Nietzsche) es pensar la voluntad de una manera autorreferencial y solipsista olvidando que la voluntad hace su aparición inherentemente en una experiencia comunitaria de vivientes (la vida antecede a la voluntad y es la voluntad misma que se expresa intersubjetiva porque ningún individuo se da la vida a sí mismo). Pero, ¿cómo aparece históricamente una voluntad colectiva? Se trata de un acto de la experiencia intersubjetiva en donde la organización (ya dada en la comunidad que precede 
al individuo) y la condición social negada se vuelcan como conciencia sobre la potentia bajo la figura "molecular" del sujeto "pueblo" que sintiéndose identificado (sensus) contiene sobre sí la experiencia de integración y de deseo de bien común (vivencia y sobre-vivencia) como voluntad general consensuada desde la vida y para la vida. Es el pueblo como hecho histórico el que encarna la voluntad general bajo distintos matices culturales, sociales, religiosos, políticos, económicos, míticos que constituyen heterogéneamente su identidad y es lo que, en últimas, lo pone en "movimiento" en los horizontes de la vida.

El "pueblo" está presupuestado para Dussel filo y onto-genéticamente en la intersubjetividad humana (2013, p. 108). Pero como término es un concepto que presenta algunas dificultades, no porque sea equívoco, sino por expresar la complejidad política y es por eso que aparece abstracto y ambiguo. Así pues, con dicho término se quiere expresar por un lado la forma vinculante de una comunidad política (otros términos con los que se apoya son Estado, nación, país, etc.) y el modo como ella se retoma así mismo en la lucha hegemónica. Por tanto, el término "pueblo" es pertinente como forma explicativa de lo político en la voluntad de vida de una comunidad.

Dussel distingue claramente en el término dos miramientos de su raíz latina: por un lado, se usa la expresión populus (al englobe total de los ciudadanos en un nuevo orden futuro donde han sido acogidas todas las necesidades en una lucha solidaria) y plebs (esa parte de pueblo insatisfecho que hace determinado reclamo en nombre de todos-populus) (2013, pp. 112-115); estas dos distinciones muestran la riqueza que lo postula como actor político, pero es el pueblo como plebs el que recoge sobre sí, con conciencia explícita, las reivindicaciones (hegemón analógico) de manera táctica y estratégica. Gramsci llama a esta determinación "bloque" porque contiene y puede desintegrarse dados sus contradicciones y conflictos según la coyuntura histórica (Dussel, 2006, p. 53). Más exactamente, el pueblo como plebs es "el bloque social de los oprimidos y excluidos" (Dussel, 2013, p. 114) que aúnan sus voluntades una vez más en medio de la comunidad política.

El análisis se hace más complejo si se piensa, ¿cómo aparece o reaparece esta potencia en un pueblo?, o de la mano de Laclau ila voluntad colectiva, es decir, popular, es ya una vía real para comprender lo relativo a una constitución ontológica como tal? (2005, p. 91). En esto, los estudios de las últimas décadas acerca del fenómeno del populismo pondrían algunos puntos: en primer lugar, habría que distinguir que el término "populismo", con el que se hace mención a la acción de un pueblo en las últimas décadas, tiene su aparición en las iniciativas rusas del siglo XIX por la lucha democrática por alcanzar la justicia y la igualdad social; pero trasladado a América Latina en el siglo XX tiene su presencia desde contextos de izquierda donde el pueblo tenía mayor representación. Lo verdaderamente valioso es la aparición como potencia más exactamente bajo los espectros del discurso y la praxis populista en el que se translucía un proyecto político hegemónico 
que nada tiene que ver con la categorización peyorativa del término que, como bien se sabe, provenía de quienes sentían la amenaza de estos movimientos del pueblo. Por ejemplo, EE.UU. al ver que políticamente se enfrentaban con la "mayoría latinoamericana" decidió cambiar las reglas del juego. Su estrategia se fue por el lado de la economía (la bancarización) y por el planteamiento de regímenes de tipo "desarrollista" que no eran más que una expansión del capital de centro (EE.UU. y Europa), con lo cual el populismo sería una especie de atraso económico ${ }^{19}$ y social. A lo que le siguió las famosas dictaduras latinoamericanas que endeudaron externamente a sus países por mantener la milicia. Los gobiernos democráticos heredaron esta pena en sus posteriores configuraciones y no les quedó más que la aceptación de la forma neoliberal de organización, con lo cual, el populismo adquirió un cambio semántico negativo como quien entorpece el progreso, pero esta connotación lingüística no durará mucho, opina Dussel, por carecer de contenido epistémico. Aunque Laclau expone que la razón política es populista porque recoge lo que mayoritariamente expresa el consenso, Dussel insiste en que las disyunciones "popular" o "populismo" tienen más realidad crítica en la categoría política de "pueblo". Dicho término no se refiere solo a la totalidad de la comunidad política establecida ya en un orden vigente, sino también a aquella parte de la "comunidad" que en un momento determinado de manera paradigmática toma conciencia de su ser "pueblo". Esta experiencia del pueblo emerge de manera especial en el reclamo por condiciones de vida más dignas y justas.

Es importante anotar que el pueblo-populus como "la comunidad política" que obedece al orden vigente puede estar incluso en cierto estado de "pasividad cómplice" con la clase dirigente (o forma de gobierno) que ha llevado a la comunidad a menores posibilidades vitales. Sin embargo, en determinados momentos puede volverse disidente o contrario a dicho orden establecido. Es entonces cuando el populus se transforma en plebs que toma conciencia de sí cuando descubre que la hegemonía establecida no cumple con su deber de cubrir las necesidades materiales (la vida misma) de la comunidad; entonces emprende un proceso (lento y luchado) de organizarse para replantear el orden vigente. Comienza a hacerlo, por ejemplo, lingüísticamente (sentido que le da Laclau a la necesidad negada que se expresa por medio del discurso) y en la praxis a través de la reivindicación que manifiestan distintos movimientos, que si bien, no son la suma del pueblo, sí expresan en nombre de él su necesidad insatisfecha. Ellos recuerdan al orden vigente la sede del poder ("el pueblo unido jamás será vencido" típica consigna de los pueblos latinoamericanos) y crean una fractura con dicho

\footnotetext{
${ }^{19}$ Valga aquí una aclaración más en defensa del término "pueblo" ya que va más allá del papel que jugó en medio de cierto marxismo estándar unido a la condición de "clase", aunque su valor está en mostrar la interconexión que el pueblo tiene con el campo económico, pero reducirlo a este campo tan solo genera una gran reducción peligrosa. Por el contrario, la "conciencia de pueblo" engendra muchas otras realidades, culturales, religiosas, sociales, etc., que no están solo mediadas por lo económico.
} 
orden. El pueblo ahora plebs ha emergido con un proyecto analógico-hegemónico (ya se irá explicando) que ha dialogado y traducido los intereses de los distintos movimientos o grupos manifestando la transversalidad de sus reivindicaciones particulares: esto no quiere decir que una reivindicación domine a las otras en el sentido de "más demanda" que las otras, ni tampoco que es imposible unir las diferencias; se trata más bien de un proceso de correspondencia analógica, que en últimas es el permiso de la distinción en la semejanza ${ }^{20}$ en donde la demanda de uno es la posibilidad de los otros. Por ejemplo, en la reivindicación de un pueblo que quiere luchar contra la esclavitud, las demandas posibles que pueden aparecer, se transparentan en lucha de la mujer negra o del indígena u otros que análogamente sufren de algo semejante.

Por lo anterior podríamos decir que el populismo, en el sentido positivo del nominal, es la forma como el "bloque histórico de los oprimidos" reclama de distintos modos (puede ser como movimiento popular u otra forma análoga) en medio de la comunidad política vigente (reflejada en la forma como procede su Estado, su nación, su país, etc.) no solo la atención a una serie de demandas, sino la sede del poder en el pueblo que hace dicha militancia por la toma de conciencia de su circunstancia.

Si se ha entendido bien la idea de Dussel acerca de la voluntad de vida que manifiesta su poder-poner mediaciones para la misma, esta no solo es visible en la cristalización-fijación del poder en la institucionalización (potestas), sino su fuerza se muestra en la reconstrucción o replanteamiento de esas mediciones (que fueron creadas para la vida) siempre que — en su clara contingencia histórica— no cumplen el motivo vital por el cual fueron hechas; si la potestas ha llegado a olvidar sus fundamentos como tal, la potencia debería "reaparecer fuertemente" de algún modo en los instrumentos formales de la ley y sobre todo de la democracia. Pero ¿qué pasa cuando los mecanismos que una sociedad-pueblo ha inventado para la aparición de la potencia encuentran limitaciones impuestas por poder vigente?, ¿cómo sucede históricamente que un orden que se ha tornado injusto (fascismo, totalitarismo, etc.) pueda ser depuesto por otro con pretensión de verdad, bondad y justicia?, o ¿cómo se abre paso la vida en contextos donde ha sido imposibilitada políticamente?

\section{Liberación e hiperpotencia: momento crítico de la Voluntad de Vida}

La voluntad de vida juega un papel importante como motivador principal de toda liberación, pues se quiere vivir (poder vivir) y alejar todo aquello que atente contra dicha existencia. Pero la liberación no es simplemente una experiencia que

\footnotetext{
${ }^{20} \mathrm{El}$ método analéctico de la filosofía de la liberación comprende bien este ejercicio comprensivo tan importante aquí.
} 
se presenta para superar determinada situación, sino que es a la vez, una vuelta (salvación) al fundamento que implica un acto de conciencia (resolución) por la circunstancia vital. El filósofo español Ortega y Gasset redescubre la importancia de propia circunstancia vital (histórica) como una forma de conciencia éticopolítica-crítica de una parte (plebs) de la comunidad política (populus).

Dicha "circunstancia"21 no solo hace referencia a un momento espacial exterior geográfico, físico u orgánico, sino que también manifiesta el "mundo exterior" y el "mundo interior" motivacional de la conciencia y de los sentidos; Ortega y Gasset lo expresa así: "Yo soy yo y mi circunstancia, y si no la salvo a ella no me salvo yo" (1981, p. 50). La circunstancia se caracteriza por su estar en torno - circum - a un yo: "él es quien da su carácter unitario y circunstancial, o sea vital" (1981, p. 51). Por tanto, el "yo" es inseparable de la circunstancia y solo tiene sentido recíprocamente. Un "yo" capaz de entrar en sí mismo, y no ser algo, sino alguien. Ese "yo" puede estar determinando por la circunstancia, pero no puede ser agotado por ella (encuéntrese en el momento histórico en que se encuentre) lo que quiere decir, que esta posibilidad es lo que permite a un sujeto la transformación y auto-transformación de su realidad.

La posesión de una circunstancia no se hace a manera de substrato de ella, sino en relación con ella; se vive y se hace vida con la circunstancia hasta el punto incluso que ella puede reflejarse en el cuerpo (concreción de la vida) como lo describe Foucault en las afecciones corporales de los micropoderes, y será esta experiencia el lugar desde donde ética y políticamente se pueden hacer las exigencias de la praxis de liberación:

Es desde esta positividad del criterio de verdad y el principio ético material de reproducción y desarrollo de la vida del sujeto ético que la negatividad de la muerte, la miseria, la opresión de la corporalidad por el trabajo alienado, la represión del inocente y de la libido, en particular de la mujer, la falta de poder político de los sujetos frente a las instituciones, la vigencia de los valores invertidos, la alienación del sujeto ético, etc., puede cobrar ahora sentido ético cabal (Dussel, 2009b, p. 311).

La toma de conciencia de una determinada circunstancia puede hacerse también de manera comunitaria, en responsabilidad solidaria por el Otro que padece la carga negativa de su momento como cuando, por ejemplo, Moisés ve el maltrato que sufre el pueblo hebreo por parte de los egipcios (Ex 2, 11 21). Este hecho quedó enmarcado en la memoria semita hasta nuestros días siendo no simplemente recordado, sino también celebrado en la Pascua Judía. Análogamente, el judío Jesús de Nazaret, en sus parábolas, propondrá dicha

${ }^{21}$ En El Tema de Nuestro Tiempo, Ortega y Gasset, afirma: "Nuestra vida, la de cada cual, es el diálogo dinámico entre "yo y sus circunstancias" [...]. El mundo es primeramente circunstancia del hombre y "a través de ésta comunica con el universo" [...] Me encontré pues desde luego, con esta doble averiguación fundamental: que la vida personal es la realidad radical" (1981, pp. 50-51). 
responsabilidad por el Otro y su circunstancia desde un "afuera de la ley" en la parábola del Buen Samaritano.

La víctima es aquel que experimenta la carga negativa de una circunstancia y puede tomar conciencia de ella porque la siente en su cuerpo: siente el hambre, la sed, la desnudez, la negación de las condiciones básicas y de realización de la misma (no es feliz). La víctima que es el que "no puede vivir" porque algo externamente a ella se lo impide ${ }^{22}$. Experimenta el dolor de una voluntad de poder fetichizada y reflejada en la potestas que elimina o debilita su voluntad de vida $^{23}$ individual y comunitaria.

Sin embargo, muchas veces frente a todo pronóstico la voluntad de vida del que "no puede vivir" se levanta creativamente —Dussel la ha llamado el "ethos de la valentía" (2013, p. 117) — para poder transformar su circunstancia con un original poder dispuesto a de-construir el orden vigente: Es ahora la conatio vitae conservandi (impulso a conservar la vida) la que emerge como un impulso vital extraordinario. Rompe los muros de la Totalidad y abre en los límites del sistema un ámbito por el que la Exterioridad irrumpe en la historia (118). A este hecho histórico es a lo que Dussel va a llamar concretamente la "hiperpotencia", que es un poder-plus que emerge históricamente desde las víctimas; es un poder creador que va más allá "para inaugurar grandes transformaciones o revoluciones, es el "tiempo-ahora" mesiánico de Benjamín" (122). Ya que la Totalidad los ha excluido, esta se fractura en el "bloque social de los oprimidos" que luchan contra ella y la transforman a través del consenso crítico de los negados ${ }^{24}$.

Con Nietzsche pero más allá de él: el pueblo así es portador de un caos (no representa un orden, un cosmos, una concordancia con la totalidad o sencillamente, ya no la desea porque no es garante de justicia) para una nueva creación; el pueblo ha de dejar aquella condición donde le han hecho ser "el hombre que no es" o "el último hombre", "el rebaño" el cual necesita sobrepasar:

\footnotetext{
${ }^{22}$ A la consideración del poder le sigue una consideración del ser, como el conatus spinoziano que solo algo externo a él puede privarlo de su existencia porque en sí mismo no posee la causa de su destrucción, con lo que Spinoza insiste en la perennidad del esfuerzo por la existencia en cada cosa.

${ }^{23}$ Dussel dice: "el pueblo antes de su lucha, es ignorado, no existe, es una cosa a disposición de los poderosos" (2013, p. 118).

${ }^{24}$ Situar geopolíticamente la propia filosofía, implica descubrir el mundo circundante desde donde se piensa. Dussel (2009a), reflexiona sobre el lugar desde donde se ha filosofado: desde la periferia o desde el centro. Esta cuestión coloca de relieve el ejercicio vital de la filosofía como interpretadora de una realidad circundante que a su vez la puede condicionar. Liberar la filosofía significa ser conscientes de las fuerzas de poder-saber que la atraviesan y de los marcos teóricos desde donde se piensa o se justifica una realidad. Dussel critica el texto de Taylor titulado Las fuentes del yo. El hacerse de la identidad moderna, porque proporciona elementos netamente eurocéntricos de interpretación de la propia identidad, o sea, del "yo" que me interesa investigar como condicionado y no por las propias circunstancias (pp. 66-76).
} 
Les quiero hablar de lo más despreciable: pero lo más despreciable es el último hombre". Y así habló Zaratustra al pueblo: ya es tiempo de que el hombre se fije su meta. Ya es tiempo de que el hombre se plante la semilla de su más alta esperanza. Su suelo es aun suficientemente rico. Pero ese suelo se volverá un día pobre y domesticado y ningún árbol podrá crecer en él [...] Yo os digo: hay que tener aún caos dentro de sí para poder dar a luz una estrella que dance. Yo os digo: aún tenéis caos dentro de vosotros (Nietzsche, 2011a, p. 5).

Es el espíritu dionisiaco, de sensación de vitalidad, danzante, de embriaguez, de "des-orden" el que reclama su "más alta esperanza", en un "aún" histórico de la circunstancia, en una posibilidad que se puede transformar, que puede ser "transvalorada" en la crítica al sistema. Quizá el hombre que se debe superar es el de la complicidad del pueblo con dicho sistema que lo ha hecho totalmente pasivo, que lo ha hecho "rebaño". Sin embargo, en contraposición con el autor alemán, no se piensa aquí en "los fuertes" opacados por los "débiles" (elementos que justificaron teóricamente el imaginario de una raza aria que se reclama históricamente a sí misma), sino en mirar críticamente el papel de los oprimidos en el proceso de liberación, como irrupción a una Totalidad que hace una "desconstrucción" política.

Si el pueblo "dentro-fuera" (populus-plebs) de la Totalidad deja de ser entonces "obediente", si tiene caos en el sentido nietzscheano, se convierte necesariamente en disidente haciendo perder el consenso hegemónico y la legitimidad del poder establecido y reclamándolo ahora sobre sí como pueblo. La Totalidad (ontológica) que había representado un orden político cargado de sentido y en donde todo cobra significado, lo pierde ahora para la experiencia de la víctima quien hace una relectura de su circunstancia vital.

Finalmente, para Dussel, el que existan víctimas, manifiesta que la Totalidad de alguna manera los ha excluido de los beneficios de un orden establecido (2013, p. 130). Si bien es cierto que en la contingencia histórica la constitución de la potestas se presupone bondadosa, verdadera y legítima (Dussel, 2009b, p. 310), también es verdadero que en la finitud ${ }^{25}$ de su miembros, la potestas no suficientemente en tensión con la potentia, puede entrar en un progresivo alejamiento del fundamento y tornarse un poder fetichizado. Sin embargo, las víctimas no solo se pueden "hacer patología de Estado" (Dussel, 2006, p. 140),

\footnotetext{
${ }^{25}$ Tanto la ética como la política de la liberación optan por una explicación de la experiencia del mal desde la materialidad negada: "La pregunta plantada por Leibniz ("Unde malum") vuelve a aparecer. El "mal" no es la "materia" o el "otro" principio co-originario como se piensa desde Plotino, y aún en cierta tradición gnóstica, que llega hasta Bôhme o Schelling, y de alguna manera a Kant y a Hegel: el principio de la determinación (principium individuationis) pareciera ser en estas tradiciones algo así como el "mal originario". Para la Ética de la liberación, en cambio, la posibilidad del mal se encuentra simplemente en la finitud humana; es decir, en la imposibilidad de un conocimiento y de una pulsión (amor) perfectos" (Dussel, 2009b, pp. 372-373).
} 
sino que son históricamente capaces de potenciación política porque recuerdan la sede del poder en el pueblo.

\section{Conclusiones}

Después del camino recorrido hasta aquí se puede afirmar que la potentia no queda diluida en la potestas. Por el contrario, provoca una continua tensión que lleva no solo a darle sentido al poder constituido, sino incluso a replantearlo en los momentos en que este ha perdido su originalidad vital.

La filosofía política de Dussel es un proyecto arquitectónico que tiene como base la voluntad de vida o potencia. En ella está el contenido material éticopolítico que da sentido a los contenidos formales de los mismos. La determinación de la política en la voluntad de vida es a la vez la condición de todo proyecto emancipador.

La política para Dussel es un "noble oficio" que implica una actitud de servicio porque entiende que el poder está en el pueblo que aúna su voluntad desde y para la vida. Si a la política le es inherente la maldad profunda expresada en la concepción de una naturaleza salvaje y egoísta, entonces solo cabe la dominación, es decir, la concepción de que solo un poder mayor sobre otros controla y disciplina las constantes amenazas que representa la individualidad. Por el contrario, una visión positiva del poder como voluntad intersubjetiva que pone mediaciones para la vida, replantea nada más y nada menos que la gran tradición teórico-política moderna y su praxis extendida hasta hoy.

El poder definido positivamente como se explicó más arriba considera una actitud más amable con el medio ambiente porque es este mismo mundo la condición para la existencia. No por nada los movimientos ecológicos han sido más visibles en esta época, aunque sus conquistas no han logrado ser todavía subsumidas en su totalidad por la política global. El poder como dominación se torna enemigo de la vida personal, comunitaria y ecológica; la aliena en todos sus estadios, quita sus suministros básicos, a tal punto de normalizar la muerte misma. Queda radicalmente en manos de los hombres y mujeres del siglo XXI y en adelante — como pretende motivar el filósofo latinoamericano- poner en marcha el poder vital o potentia que sitúe a la potestas con mayor pretensión de verdad, bondad y justicia universal para que la vida misma quede amparada en todas sus formas hasta las generaciones póstumas. 


\section{Referencias}

Aristóteles (2011). Metafísica. Madrid: Gredos.

Agamben, G. (2013). Homo Sacer. Valencia: Pre-textos.

Descartes, R. (2013). Discurso del Método y Meditaciones Metafísicas. Ciudad de México: Editorial Tomo.

Dussel, E. (2001). Hacia una filosofía Política Crítica. Bilbao: Desclée de Brouwer.

Dussel, E. (2006). 20 tesis de Política. Ciudad de México: Siglo XXI Editores.

Dussel, E. (2009a). Política de la Liberación. Madrid: Trotta.

Dussel, E. (2009b). Ética de la Liberación en la Edad de la Globalización y de la Exclusión. Madrid: Trotta.

Dussel, E. (2011). Carta a los Indignados. Ciudad de México: La Jornada.

Dussel, E. (2013). Para una Política de la Liberación. Buenos Aires: Las Cuarenta.

Nietzsche, F. (2008). La Voluntad de Poder. Madrid: Ediciones Algaba.

Nietzsche, F. (2011a). Así Habló Zaratustra. Madrid: Clásicos.

Nietzsche, F. (2011b). Ecce Homo. Ciudad de México: Ediciones Leyenda.

Ortega y Gasset, J. (1981). El tema de nuestro tiempo. Madrid: Alianza Editorial.

Laclau, E. (2005). La Razón Populista. Buenos Aires: Fondo de Cultura Económica.

Parménides y Heráclito (1977). Fragmentos. Buenos Aires: Ediciones Orbis.

Spinoza, B. (2005). Tratado Teológico político. Buenos Aires: Libertador.

Spinoza, B. (2013). Ética. Madrid: Alianza Editorial. 